\title{
Oxidative Stress Induction in Monosex Nile Tilapia (Oreochromis niloticus, Linnaeus, 1758): A Field Study on the Side Effects of Methyltestosterone
}

\section{Alaa El-Din H. Sayed ${ }^{1 *}$ and Nasser S. Abou Khalil ${ }^{2}$}

${ }^{1}$ Zoology Department, Faculty of Science, Assiut University, 71516 Assiut, Egypt

${ }^{2}$ Medical Physiology Department, Faculty of Medicine, Assiut University, Assiut, Egypt

\begin{abstract}
In this survey, fishes were obtained from four localities: Assiut as a control and Beheira, Alexandria and Kafr EL-Sheikh; three farms from each governate as farmed monosex produced using Methyltestosterone (MT). Serum MT, total antioxidant capacity (TAC), malondialdehyde (MDA), and total peroxides (TPX) were estimated, followed by calculation of oxidative stress index (OSI). MT concentration in the serum of fishes farmed at Assiut showed no detectable levels of hormonal residues, while the monosex farms showed high levels of MT concentration in the serum of the sampled fishes. In comparison with control fishes of Assiut farms, serum TAC levels of monosex fishes collected from farms of Beheira and Alexandria were significantly lower. Serum TPX content of the monosex fishes obtained from Alexandria farms were significantly higher than the wild fishes obtained from Assiut farms. Calculated from ratio of serum TPX content and TAC concentration, OSI illustrated a significant difference between control fishes collected from Assiut and monosex fishes collected from Beheira. Although few significant changes were found in the examined oxidative stress endpoints, the results of this work put our foot in the beginning of road to link hormonally sex reversal practice with oxidative stress induction, and provocative for other researchers to invade this field of research more deeply utilizing more specific relevant markers and cutting-edge techniques.
\end{abstract}

Keywords: Musculinizing inducer; Sex reversed tilapia; Malondialdhyde; Total antioxidant capacity; Total peroxide

\section{Introduction}

Recently, production of tilapia in Egypt exceeds that of common carp make it the most commonly cultured fish species owing to some favorable features appropriated for aquaculture industries such as high tolerance to adverse environmental conditions, resistance to disease, efficient food conversion, fast growth rate, good consumer acceptance, and ease of spawning $[1,2]$.

Taking into account the wide spectrum of economic and rearing benefits, sex reversal techniques are paid greater attention over the time in aquacultured fish systems. Achievement of high growth rate, prevention of large energy dissipation into reproduction and courtship behaviour, reducing aggressiveness, uniformity in size, avoiding undesirable effects of sexual maturation on appearance and meat quality, and reducing undesirable environmental impacts are the main contributory factors in rising the interest about monosex fish cultures [3] One of the most practiced sex reversal techniques is hormonal induction especially using methyltestosterone that has been test in more than 25 fish species [4]. However, this technique faces several limitations and disadvantages like time and cost consumption, low survival of sex reversed male or female, delayed sexual maturity, sterility at high dose, paradoxical sex reversal, and carcinogenicity of hormonal residues and other health hazards $[5,6]$.

Oxidative stress is a situation characterized by an imbalance between increased production of oxidant species and/or decreased efficacy of the antioxidant defense system [7] leading acromolecule to damage including lipid peroxidation, protein crosslinking, DNA damage, changes in growth and function of cells [8]. The investigation of this imbalance is difficult due to the limited availability of specific biomarkers of oxidative stress, and the fact that measurement of individual antioxidant may give misleading picture because antioxidants work in concert through chain breaking reactions. Therefore, analysis of total antioxidant capacity may be the most relevant investigation [9] and take into consideration the cumulative synergistic action of all the antioxidants present in the sample providing an integrated parameter rather than the simple sum of measurable antioxidants [10]. Malondialdhyde (MDA) is the product of polyunsaturated fatty acid peroxidation and a key reflector of free radical-scavenging and production capability in many pathological conditions of fish species $[11,12]$. Oxidative stress index that is as a combined product of prooxidants/antioxidants ratio gives a bidirectional mirror image to the overall oxidative/reductive potency of the given specimen $[13,14]$.

Oxidative stress in area of marine fish farming is important both for the health of farmed fish and for seafood quality. It adversely impacted fish welfare on several levels as growth [15] reproduction [16], and immunity [17].

Two face impacts of androgenic steroids on redox homeostatic status is emerged from literature. They range from pro-oxidant properties in pre-spawing brown trout (Salmo trutta) and zebra finch $[18,19]$, or even oxidative stress inducers in some studies [20-22], to antioxidant influences in several in vivo and in vitro models [23-25]. It is worthy to note that pro-oxidant effects of androgen can be evoked indirectly by its metabolites, estradiol, whereas other metabolite, $5 a$-dihydrotestosterone, stimulates signal expression [26]. However, there is no available data until now about modulation of peroxidative and antioxidants diagnostic markers in monosex farms produced by methyltestosterone (MT) administration. Inclusion of such aspects

*Corresponding author: Alaa El-Din H. Sayed, Faculty of Science, Assiut University, 71516 Assiut, Egypt, Tel: +020882411444; E-mail: alaa_h254@yahoo.com

Received December 01, 2015; Accepted February 01, 2016; Published March 04, 2016

Citation: Sayed AEDH, Khalil NSA (2016) Oxidative Stress Induction in Monosex Nile Tilapia (Oreochromis niloticus, Linnaeus, 1758): A Field Study on the Side Effects of Methyltestosterone. J Aquac Res Development. 7: 416. doi:10.4172/2155-9546.1000416

Copyright: (c) 2016 Sayed AEDH, et al. This is an open-access article distributed under the terms of the Creative Commons Attribution License, which permits unrestricted use, distribution, and reproduction in any medium, provided the original author and source are credited. 
is of utmost importance to widen the scope in this area of research and resolve the controversies. Therefore, this paper tries to focus on a field relevant problem going a forward step in understanding the unfavorable impacts of hormonal sex reversal in fish populations with special emphasis on the potential induction of oxidative stress using methyltestosterone in monosex Nile tilapia. To accomplish this goal, water quality, serum and muscle MT, TAC as a cytoprotectant indicator, and both of MDA and TPX as pathogenetic effectors were measured, followed by calculation of oxidative stress index (OSI) as a reflector of the oxidant/antioxidant status in three aquafarms of four governments in Egypt using Assiut fish farms as a control to confirm our previous study results as genotoxic effects of MT [27,28].

\section{Materials and Methods}

\section{Sample collection and characterization of water quality and morphometric outcome measures of the studied fishes}

Healthy fishes of The Nile tilapia (Oreochromis niloticus) were caught from Assiut farms as control and three farms of Beheira, Alexandria and Kafr EL-Sheikh as monosex farms in Egypt. The data about water quality assessment and age, weight, and length of the collected fishes already published in previous study [28].

\section{Serum and muscle methyltestosterone measurement}

Their levels were determined by enzyme-linked immunosorbent assay reader (Stat Fax-200, Awareness Technology company, USA) using a commercially available kit (Art. Nr. R3601) according to the instructions of manufacturer (R-Biopharm GmbH, Darmstadt, Germany). Briefly, all reagents were brought to room temperature and reconstituted as recommended using the provided reagents. $50 \mu \mathrm{l}$ of diluted enzyme conjugate was added to the bottom of each well of 96-well micotiter plate, followed by addition of $50 \mu \mathrm{l}$ of standard and prepared sample to separate duplicate wells. After addition of $50 \mu \mathrm{l}$ of diluted MT antibody to each well, the content of each well was mixed thoroughly, and incubated overnight $(12-16 \mathrm{~h})$ at $2-8^{\circ} \mathrm{C}$. The liquid was poured out of the wells and the microwell holder was tapped upside down vigorously against absorbent paper to ensure complete removal of liquid from the wells. The wells were filled three times, each time with $250 \mu \mathrm{l}$ of distilled water and the liquid was poured out as the previous step. $50 \mu \mathrm{l}$ of each of substrate and chromogen was pipetted into each well followed by mixing the content thoroughly and incubation of the microtiter plate for 30 minutes at room temperature. After addition of $100 \mu \mathrm{l}$ of stop solution to each well, the contents were mixed well and the absorbance was measured at $450 \mathrm{~nm}$ against air blank within 60 minutes. The mean values of the absorbance were obtained for the standards and the samples were divided by the absorbance value for the first standard (zero standard) and multiplied by 100 . The zero standard was made equal to $100 \%$, and the absorbance values were quoted in percentages. The values calculated for the standards were entered in a system of coordinates on semilogarithmic graph paper against MT concentration in (ng/l), after that MT concentration in $\mathrm{ng} / \mathrm{l}$ corresponding to \% absorbance of each sample was read from the calibration curve. The detection limit of this assay is $0.2 \mu / 1$, and the coefficients of variation of the absorbance units obtained from 3 independent experiments entered against the corresponding MT concentrations are so low that good reproducibility (interassay variation) of the results is ensured. The specificity of the assay was determined by analyzing the cross-reactivity to corresponding substances.

\section{Total antioxidant capacity measurement}

Serum TAC was measured according to protocol given by
Koracevic [29,30]. Briefly, $0.02 \mathrm{ml}$ of distilled water was added in blank tube to $0.5 \mathrm{ml}$ of $\mathrm{R} 1\left(\mathrm{H}_{2} \mathrm{O}_{2}\right.$ diluted 1000 times before use), whereas 0.02 $\mathrm{ml}$ of sample was added in sample tube. Then, the tubes were mixed and incubated 10 minutes at $37^{\circ} \mathrm{C}$. Working reagent was prepared by mixing equal volumes of R2 (chromogen) and R3 (enzyme and buffer) immediately before use, and then $0.5 \mathrm{ml}$ of the working reagent was added to both of blank and sample tubes. The contents were mixed and the tubes were shaken and then incubated 5 minutes at $37^{\circ} \mathrm{C}$. The absorbance of blank and sample were read immediately against distilled water at $505 \mathrm{~nm}$. Serum TAC, MDA, and TPX were measured colorimetrically using spectrophotometer (Spectronic 21, Moton Roy Company, USA).

\section{Malondialdhyde measurement}

According to Ohkawa procedure, $1 \mathrm{ml}$ of chromogen was pipetted into tubes labeled as sample, standard, and blank. Then $0.2 \mathrm{ml}$ of sample and standard were added to the corresponding tubes. The contents were mixed and the tubes were shaken, covered with screw cap, and then heated in boiling water bath for 30 minutes. After cooling the mixture, $0.2 \mathrm{ml}$ of sample was added to blank tube and the content was mixed well. The absorbance of sample against blank, and standard against distilled water were read at $534 \mathrm{~nm}$.

\section{Total peroxide measurement}

It was assessed following [31] $\mathrm{R} 1$ consists of $4.8 \mathrm{mg}$ ammonium ferrous sulfate, $5 \mathrm{ml}$ distilled water, $130 \mu \mathrm{l}$ conc sulphuric acid, $4 \mathrm{mg}$ xylenol orange, and $45 \mathrm{ml}$ absolute ethanol containing $40 \mathrm{mg}$ butylated hydroxyl toluene were added and dissolved by stirring. The blank solution was prepared by the same steps that of reagent without adding ammonium ferrous sulphate. $50 \mu \mathrm{l}$ of serum was added to $1.25 \mathrm{ml}$ of $\mathrm{R} 1$. The contents were mixed and the tubes shaken, and then incubated at room temperature for half hour, followed by centrifugation at 5000 rpm for $3 \mathrm{~min}$ in eppendrof and then measured against blank at $560 \mathrm{~nm}$

\section{Calculation of serum oxidative stress index}

It is the percent ratio of TPX content to TAC concentration, and measured according to the following equation [31]:

$$
\text { OSI }=(\mathrm{TPX}, \mu \mathrm{M} / \mathrm{L}) /(\mathrm{TAC}, \mu \mathrm{M} / \mathrm{L}) \times 100
$$

\section{Statistical analysis}

The data were expressed as means \pm standard error of the mean (SEM). Significant differences between groups were analyzed using one-way ANOVA followed by least significant difference (LSD) test for multiple comparisons using SPSS software, version 16. Differences were considered statistically significant at $\mathrm{P}<0.05$.

\section{Ethical statement}

The study was carried out in accordance with the Egyptian laws and University guidelines for the care of experimental animals. All procedures of the current work have been approved by the Committee of the Faculty of Science, Assiut University, Egypt.

\section{Results}

Sex reversed fishes characterized with a marked accumulation of MT in the serum and muscle

Figures $1 \mathrm{a}$ and $1 \mathrm{~b}$ reveals MT concentrations in the serum and muscle of sampled fishes from the monosex farms in comparison with Assiut farms $[27,28]$. They showed no detectable levels of hormonal 


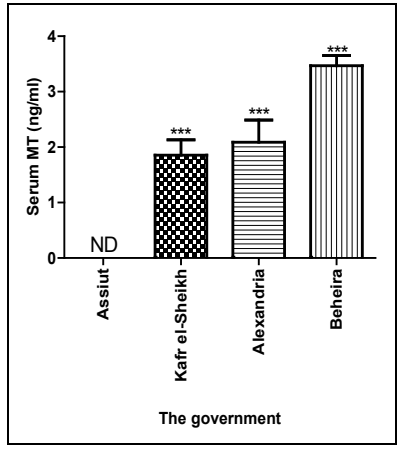

(a)

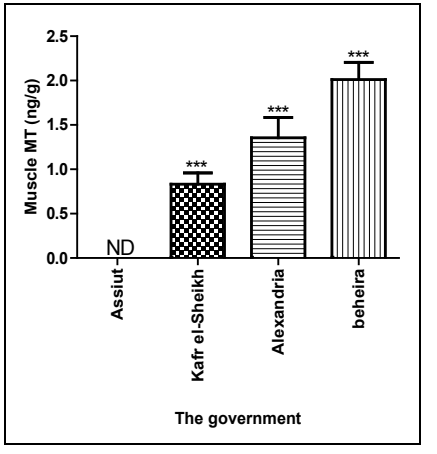

(b)
Figure 1: Graphic representation of methyltestosterone (MT) levels in blood serum (a) and muscle (b) of Nile tilapia (Oreochromisniloticus) collected from Assiut farms as control, and three farms of Beheira, Alexandria, and Kafr elSheikh as monosex farms.

ND: Non detectable.

residues in Assiut farms, while the monosex farms exhibited high levels of MT concentrations in the serum and muscle of the sampled fishes in a high significant $(\mathrm{p}<0.001)$ manner versus control farms.

\section{Oxidative stress induction under MT load in all male sex fishes}

As shown in Table 1, Figures $2 \mathrm{a}$ and $2 \mathrm{~b}$ serum TAC levels of monosex farms of Beheira $(0.794 \pm 0.102 \mu \mathrm{M} / \mathrm{L})$ were significantly lower than those of Kafr EL-Sheikh $(0.959 \pm 0.029 \mu \mathrm{M} / \mathrm{L})$ and control farms of Assiut $(1.006 \pm 0.030 \mu \mathrm{M} / \mathrm{L})(\mathrm{P}<0.05$ and $\mathrm{P}<0.01$, respectively). With respect to serum TPX content, the control fishes from Assiut farms were $1.520 \pm 0.050 \mu \mathrm{M} / \mathrm{L}$ that were significantly $(\mathrm{P}<0.01)$ lower than the monosex farms of Alexandria $(1.759 \pm 0.083 \mu \mathrm{M} / \mathrm{L})$. Also, there was a significant difference $(\mathrm{P}<0.01)$ between monosex farms of Beheira $(1.531 \pm 0.054 \mu \mathrm{M} / \mathrm{L})$ and Alexandria. Supersingly, no significant difference could be monitored regarding serum MDA levels neither between monosex farms of the three governments (Kafr EL-Sheikh, Alexandria, and Beheira) and control farms of Assiut on one hand, nor between the monosex farms themselves on the other hand. Calculated from the ratio of serum TPX content and TAC concentration, OSI revealed an imbalance between reactive oxygen species (ROS) and antioxidant defense mechanisms in the given specimens. The only significant difference $(\mathrm{P}<0.05)$ that could be detected was between control fishes from Assiut $(151.715 \pm 5.193 \%)$ and monosex fishes from Beheira (250.854 $\pm 59.894 \%)$ (Table 2).

\section{Discussion}

One expanding area of research not yet fully studied to date is the potential negative effects of androgens on aquacultures during production of monosex fish farms. Their detailed mechanistic pathways have not been completely elucidated and will be the subject of future experiments to expand the knowledge base and resolve discrepancies. Understanding their pathophysiological mechanisms pave the way for optimal therapeutical strategies for rising masculinized fishes without adverse impacts on fish health condition and welfare. With high levels of MT in their muscles, it may represent a major surprise to know that these currently studied masculinized fishes indeed are market-ready ones. Given that monosex fish is a vehicle for highly concentrated androgen, the problem limits may surpass fish burden to human food safety. Few significant changes in the parameters along with estimation of general index of oxidative stress as MDA in this study make further confirming researches utilizing more specific and relevant oxidative stress markers requisite before come to the radical conclusion that application of MT in tilapia resulted in disruption of radicalsscavenging/production systems in all male production process. But this study provides a driving force for other researchers to uncover this key area of knowledge in more details.

Inclusion of MT in Nile tilapia feeding resulted in a slight but significant depletion of serum TAC levels of monosex fishes of Beheira farms giving insight into implication of this intervention on the overall enzymatic and non-enzymatic antioxidants and crosslinked with high MT residue in their fish serum and muscle. In accordance, brown trout (Salmo trutta, L.) with higher testosterone levels prior to spawning have higher levels of oxidative damage exemplified by decreased antioxidant capacity at the time of spawning. In addition, testosterone induced changes in the oxidative status of rat testis by reducing TAC [32]. Enhanced reactive oxygen species production, and depleted antioxidant enzyme levels and activities are linked to testosterone administration in several published articles [3335]. It seemed that increased reactive oxygen species generation, as manifested by increased TPX and MDA levels in this study, consumed antioxidant reserves of sex reversed Nile tilapia. Genomic techniques, such as real-time quantitative polymerase chain reaction allow the simultaneous measurement of genes and their expression that involved in multiple biochemical pathways. Assessment of mRNA antioxidant enzyme genes expression in human vascular endothelial cells treated with supra-physiological doses of testosterone enanthate provides mechanistic information relating testosterone exposure to oxidative stress initiation [36]. In contrast, dehydroepiandrosterone as an adrenal androgen increased total glutathione content and reduced glutathione in young and old healthy rats [37], and glutathione-S-transferase in aged rats [38]. In addition, testosterone reversed the adverse effects of ovariectomy and 3-nitropropionic acid on reduced glutathione content and glutathione peroxidase activity in striatum of rats [39], increased activities of superoxide dismutase and glutathione peroxidase in cardiomyocytes of testicular feminized and castrated male mice [40], and total antioxidation capability in mice [41] In vitro, it enhanced catalase activity in undifferentiated mouse neuroblastoma cells [42], and glutathione reductase activity, and increased the content of thiol groups in human neutrophils [43]. Moreover, there are no marked changes in enzymatic antioxidant activities in male rat macrophages following testosterone supplementation [44].

\begin{tabular}{|l|l|l|l|l|}
\hline $\begin{array}{l}\text { Parameters/ } \\
\text { Governments }\end{array}$ & Assiut & Kafr el- Sheikh & Alexandria & Beheira \\
\hline Serum MT $(\mathrm{ng} / \mathrm{ml})$ & ND & $2.03 \pm 0.16^{\star \star *}$ & $2.32 \pm 0.31^{\star * *}$ & $3.47 \pm 0.19^{\star * *}$ \\
\hline Muscle MT $(\mathrm{ng} / \mathrm{g})$ & ND & $0.93 \pm 0.07^{\star * *}$ & $1.54 \pm 0.15^{\star \star *}$ & $2.01 \pm 0.19^{\star \star *}$ \\
\hline
\end{tabular}

Table 1: Methyltestosterone (MT) levels in blood serum and muscle of Nile tilapia (Oreochromis niloticus) collected from Assiut farms as control, and three farms of Beheira, Alexandria, and Kafr el-Sheikh as monosex farms.

\begin{tabular}{|l|c|c|c|c|}
\hline $\begin{array}{l}\text { Parameters/ } \\
\text { Governments }\end{array}$ & Assiut & Kafr el- Sheikh & Alexandria & Beheira \\
\hline TAC $(\mu \mathrm{M} / \mathrm{L})$ & $1.006 \pm 0.030$ & $0.959 \pm 0.029$ & $0.846 \pm 0.031$ & $0.794 \pm 0.102^{*}$ \\
\hline $\mathrm{MDA}(\mathrm{nmol} / \mathrm{ml})$ & $4.082 \pm 1.201$ & $4.393 \pm 2.845$ & $5.734 \pm 1.422$ & $5.630 \pm 2.013$ \\
\hline $\mathrm{TPX}(\mu \mathrm{M} / \mathrm{L})$ & $1.520 \pm 0.050$ & $1.625 \pm 0.049$ & $1.759 \pm 0.083^{\star *}$ & $1.531 \pm 0.054$ \\
\hline OSI $(\%)$ & $151.715 \pm 5.193$ & $171.160 \pm 8.888$ & $210.042 \pm 11.983$ & $250.854 \pm 59.894^{*}$ \\
\hline
\end{tabular}

Table 2: Impact of methyltestosterone supplementation on serum total antioxidant capacity (TAC), malondialdhyde (MDA), total peroxide (TPX), and oxidative stress index (OSI) of fish collected from Assiut farms as control, and three farms of Beheira, Alexandria, and Kafr el-Sheikh as monosex farms. 

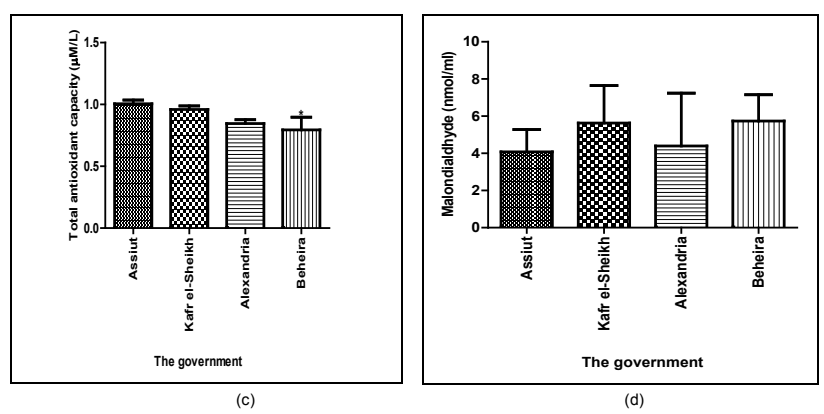

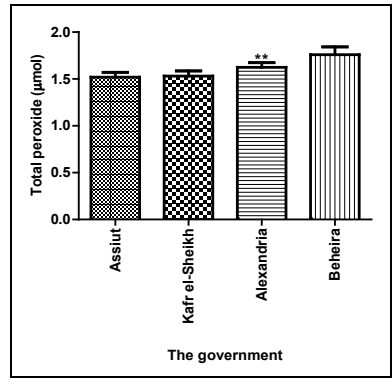

(e)

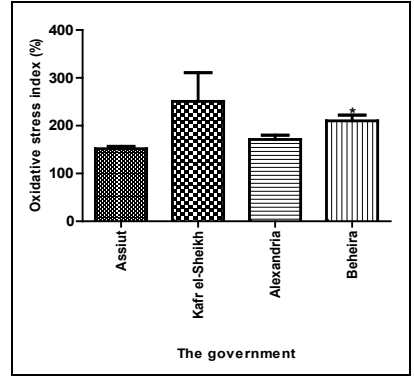

(f)
Figure 2: Graphic representation of changes in serum total antioxidan capacity (c), malondialdhyde (d), total peroxide (e), and oxidative stress index (f) of fishes collected from Assiut farms as control, and three farms of Beheira, Alexandria, and Kafr el-Sheikh as monosex farms.

Serum TPX concentrations of sex reversed fishes in Alexandria aquacultures were somewhat higher than untreated fishes in Assiut aquacultures. A clear vision to available publications supplies us with numerous examples for the close association between further oxidative stress inducing modulators and end products of peroxidative injury. For example, in Nile tilapia infected with Aphanomyces laevis and Phoma herbarum by water bath exposure and intramuscular injection, TPX and lipid peroxidation increased in both gills and mytomal muscles [45]. Similarly, mercuric chloride increased TPX in livers, kidneys, and gills of female catfish [46]. Cellular peroxide and lipid peroxidation end products increased markedly in gills of brown mussels (Perna perna) exposed for 7 and 21 days to zinc chloride [47].

Strikingly, there was no significant difference in serum MDA levels; however to some extent they were still higher in the monosex farms of the three governments (Kafr EL-Sheikh, Alexandria and Beheira) against control farms of Assiut. Indeed the data concerning androgen/ MDA relationship are inconclusive. Testosterone administration increased MDA in serum and testis of rabbits, liver, left ventricle and testicular homogenate of rats, and prostate of mice [48-51]. Conversely, it reduced levels of lipid peroxidation products in striatum of ovariectomized mice, liver of castrated and benzene treated rats, vanadium-induced testicular toxicity, intestinal ischemia/reperfusion, and brain tissues in rats [52-55]. We must keep in mind that MDA is not only the most studied indicator molecule of peroxidative damage, but also interacts with DNA and proteins to generate mutagenic and atherogenic by products [56] adding new dimension to elevation of this diagnostic marker.

OSI gives a summarized picture for the whole oxidant/antioxidant landmarks and goes behind the same successive order as that of serum and muscle MT offering an exactly copy/paste image. Among a wide range of oxidative stress indicators, it is a promising comparative index representing the interplay between the radical generating factors and their counterplayers. Even though the only slight significant difference that could be traced in OSI was between control fishes from Assiut and monosex fishes from Beheira OSI of fishes of two other sex reversed culture medium was slightly higher, but not significantly, than that of non-manipulated fishes. Actually, this biodiagnostic reflector increased in additional several oxidative stress-linked models as hyperoxia in Atlantic cod, arsenite toxicity in goldfish, diabetes, hepatic ischemia/ reperfusion, and iron overload-induced cardiac dysfunction in rats [57-60]. Elevation of OSI of hormonally masculinized fishes could be due to increased TPX and decreased TAC. The present data give insight about oxidant/antioxidant balance shifting towards oxidant side but still need confirmation by other studies demonstrating the dark side of excess testosterone.

To sum up, undesirable impact of MT over dose on oxidants/ antioxidants systems in monosex Nile tilapia was manifested by slight but still significant overproduction of MDA and TPX with corresponding diminution of TAC resulting in increased OSI that correlated with serum and muscle MT concentrations. Estimation of more sensitive, specific, and reproducible bio-reflectors of oxidative stress is essential to prove finally the close relationship between MT application in fish aquacultures and peroxidative injury. Continuation in exploring the negative impacts of MT on fish welfare necessities further investigations on the potential oxidative stress-associated pathological conditions. Transportation of highly concentrated MT through aquatic food chain implicates the plausible human health affliction that needs epidemiological studies focus on relationship between MT and various aspects of health hazard in populations that depend on seafood as a main constituent of their diet. Also, these data open a new window for the researchers to look for alternative ideal sex reversal agents with minimal side effects on fish health conditions as a future recommendation.

\section{References}

1. Asad F, Ahmed I, Saleem M, Iqbal T (2010) Hormonal masculinization and growth performance in Nile Tilapia (Oreochromis niloticus) by androgen administration at different dietary protein levels. Int J Agric Biol 12: 939-943.

2. El-Saidy D, Gaber M (2005) Effect of dietary protein levels and feeding rates on growth performance, production traits and body composition of Nile tilapia Oreochromis niloticus (L.) cultured in concrete tanks. Aquaculture Research 36: 163-171

3. Beardmore J, Mair G, Lewis R (2001) Monosex male production in finfish as exemplified by tilapia: applications, problems, and prospects. Aquaculture 197 283-301.

4. Pandian T, Sheela S (1995) Hormonal induction of sex reversal in fish Aquaculture 138: 1-22.

5. Kavumpurath S, Pandian T (1993) Deterimination of labile period and critical dose for sex estrogens in Betta splendens. Indian J Exp Biol 31: 16-20.

6. Pandian T (1994) Endocrine sex reversal in fishes: Masculinization evokes greater stress and mortality. Curr Sci 66: 240-243.

7. Gosmaro F, Marco B, Silva B, Giorgio B, Enrico P, et al. (2013) Measurement of total antioxidant capacity of human plasma: setting and validation of the CUPRAC-BCS method on routine apparatus ADVIA 2400. Talanta 115: 526532.

8. Ehsaei M, Mehdi K, Mohammad H, Daryoush H (2014) Prooxidant-antioxidant balance in patients with traumatic brain injury. Acta neurologica Belgica 115: 69-73.

9. Konuganti K, Hema S, Sameer Z, Wilma D, et al. (2012) A comparative evaluation of whole blood total antioxidant capacity using a novel nitroblue tetrazolium reduction test in patients with periodontitis and healthy subjects: $A$ randomized, controlled trial. J Indian Soc Periodontol 16: 620-622.

10. Ghiselli A, Mauro S, Fausta N, Cristina S (2000) Total antioxidant capacity as 
Citation: Sayed AEDH, Khali NSA (2016) Oxidative Stress Induction in Monosex Nile Tilapia (Oreochromis niloticus, Linnaeus, 1758): A Field Study on the Side Effects of Methyltestosterone. J Aquac Res Development. 7: 416. doi:10.4172/2155-9546.1000416

Page 5 of 6

a tool to assess redox status: critical view and experimental data. Free Radic Biol Med 29: 1106-1114.

11. Feng M, Qu R, Ying L, Zhongbo W (2013) Biochemical biomarkers in liver and gill tissues of freshwater fish Carassius auratus following In Vivo exposure to hexabromobenzene. Environ Toxicol 29: 1460-1470.

12. Mozhdeganloo Z, Heidarpour M (2014) Oxidative stress in the gill tissues of goldfishes (Carassius auratus) parasitized by Dactylogyrus spp. J Parasit Dis 38: 269-72.

13. Karlsson A, Lene S, Rosseland B, Anders K (2011) Changes in arterial PO(2), physiological blood parameters and intracellular antioxidants in free-swimming Atlantic cod (Gadus morhua) exposed to varying levels of hyperoxia. Fish Physiol Biochem 37: 249-258.

14. Perez-Jimenez et al. (2012) The effect of dietary methionine and white tea on oxidative status of gilthead sea bream (Sparus aurata). Br J Nutr 108: 12021209.

15. Betancor M, Almaida P, Sprague M, Tocher R, Hemandez A (2015) Roles of selenoprotein antioxidant protection in zebrafish, Danio rerio, subjected to dietary oxidative stress. Fish physiology and biochemistry 41: 705-720.

16. Wilson S, Samantha M, Jessica J, Trisha A, David A, et al. (2014) Oxidative stress in Pacific salmon (Oncorhynchus spp.) during spawning migration. Physiological and Biochemical Zoology 87: 346-352.

17. Wei K, Yang J (2015) Oxidative damage of hepatopancreas induced by pollution depresses humoral immunity response in the freshwater crayfish Procambarus clarkii. Fish \& shellfish immunology 43: 510-519.

18. Alonso-Alvarez C, Sophie B, Bruno F, Olivier C, Gabriele, et al. (2007) Testosterone and oxidative stress: the oxidation handicap hypothesis. Proceedings. Biological sciences/The Royal Society 274: 819-825.

19. Hoogenboom M, Metcalfe B, Ton G, Bonnie V, David C, et al. (2012) Relationship between oxidative stress and circulating testosterone and cortisol in pre-spawning female brown trout. Comp Biochem Physiol A Mol Integr Physiol 163: 379-387.

20. Goldfarb A, Mclntosh K, Boyer T (1996) Vitamin E attenuates myocardial oxidative stress induced by DHEA in rested and exercised rats. Journal of applied physiology 80: 486-490.

21. Kumar D, Deepab P, Muthaiyan R, Periasamy M, Velliyur G, et al. (2012) Protective effect of Crataeva nurvala bark against MNU and testosterone induced oxidative stress in liver of male albino rats. Biomedicine \& Aging Pathology 2: 94-98.

22. Prasad S, Neetu K, Shukla Y (2006) Modulatory effects of diallyl sulfide against testosterone- induced oxidative stress in Swiss albino mice. Asian J Androl 8: 719-723.

23. Chen J, Lin X, Congxin H (2014) DHEA inhibits vascular remodeling following arterial injury: a possible role in suppression of inflammation andoxidative stress derived from vascular smooth muscle cells. Mol Cell Biochem 388: 7584.

24. Eleawa S, Saki H, Hussien M, Alkhateeb M (2013) Effect of testosterone replacement therapy on cardiac performance and oxidative stress in orchidectomized rats. Acta physiologica 209: 136-147.

25. Mostafa T, Rashed L, Kotb K, Taymour M (2012) Effect of testosterone and frequent low-dose sildenafil/tadalafil on cavernous tissue oxidative stress of aged diabetic rats. Andrologia 44: 411-415.

26. Casagrande S, Costantini D, Tagliavini J, Dell'omo G (2012) Differential effects of testosterone metabolites oestradiol and dihydrotestosterone on oxidative stress and carotenoid-dependent colour expression in a bird. Behav Ecol Sociobiol 66: 1319-1331.

27. Sayed A (2015) Erythrocytes alterations of monosex tilapia (Oreochromis niloticus, Linnaeus, 1758) produced using methyltestosterone. Egyptian Journal of Aquatic Research.

28. Sayed A, Moneeb R (2015) Hematological and biochemical characters of monosex tilapia (Oreochromis niloticus, Linnaeus, 1758) cultivated using methyl testosterone. The Journal of Basic and Applied Zoology 72: 36-42.

29. Koracevic D, Koracevic G, Djordjevic V, Andrejevic S, Cosic V, et al. (2001) Method for the measurement of antioxidant activity in human fluids. Journal of Clinical Pathology 54: 356-361.

30. Ohkawa H, Nobuko O, Kunio Y (1979) Assay for lipid peroxides in animal tissues by thiobarbituric acid reaction. Anal Biochem 95: 351-358.

31. Harma M, Muge H, Ozcan E (2005) Measurement of the total antioxidant response in preeclampsia with a novel automated method. European Journal of Obstetrics, Gynaecology, and Reproductive Biology 118, 47-51.

32. Tothova L, Celec P, Ostanikova D, Okuliarova M, Zeman M (2013) Effect of exogenous testosterone on oxidative status of the testes in adult male rats. Andrologia 45: 417-423.

33. Chainy G, Samantaray S, Samanta L (1997) Testosterone-induced changes in testicular antioxidant system. Andrologia 29: 343-349.

34. Klapcinska B, Jagsz S, Sadowska E, Jan G, Kempa K, Langfort J, et al. (2008) Effects of castration and testosterone replacement on the antioxidant defense system in rat left ventricle. The Journal of Physiological Sciences 58: 173-177.

35. Victor V, Milagros R, Celia B, Susana R, Marcelino G, et al. (2014) Mitochondrial impairment and oxidative stress in leukocytes after testosterone administration to female-to-male transsexuals. The Journal of Sexual Medicine 11: 454-461.

36. Skogastierna C, Maja H, Anders R, Lena E, et al. (2013) A supraphysiological dose of testosterone induces nitric oxide production and oxidative stress. European Journal of Preventive Cardiology 21: 1049-1054.

37. Jacob M, Daiane J, Alev S, Matheus P, Tarsila B, et al. (2011) Dehydroepiandrosterone improves hepatic antioxidant reserve and stimulates Akt signaling in young and old rats. The Journal of Steroid Biochemistry and Molecular Biology 127: 331-336

38. Jacob M, Daiane J, Alev S, Matheus P, Tarsila B, et al. (2010) Redox imbalance influence in the myocardial Akt activation in aged rats treated with DHEA Experimental Gerontology 45: 957-963.

39. Tunez I, Montserat F, Juan A, Francisco J, Joise P, et al. (2007) Effect of testosterone on oxidative stress and cell damage induced by 3- nitropropionic acid in striatum of ovariectomized rats. Life Sci 80: 1221-1227.

40. Zhang L, Saizhu W, Yunjun R, Lei H, et al. (2011) Testosterone suppresses oxidative stress via androgen receptorindependent pathway in murine cardiomyocytes. Mol Med Rep 4: 1183-1188.

41. Jia J, Wu Y, Zhou X, Wang Y (2012) Effects of testosterone propionate on oxidative stress and the expression of spleen cytokine genes in endosulfantreated mice. Journal of Environmental Pathology, Toxicology and Oncology 31: $17-26$

42. Chisu V, Manca P, Zedda M, Lepore G, Gadau S, et al. (2006) Effects of testosterone on differentiation and oxidative stress resistance in C1300 neuroblastoma cells. Neuro Endocrinology Letters 27: 807-812.

43. Marin D, Anaysa P, Rita D, Rui C, Roseman O, et al. (2010) Testosterone suppresses oxidative stress in human neutrophils. Cell Biochemistry and Function 28: 394-402.

44. Azevedo R, Lacava Z, Moyasaka C, Chaves S, Cun R, et al. (2001) Regulation of antioxidant enzyme activities in male and female rat macrophages by sex steroids. Brazilian Journal of Medical and Biological Research 34: 683-687.

45. Ali E, Hashem M, Salahy M (2011) Pathogenicity and oxidative stress in Nile tilapia caused by Aphanomyces laevis and Phoma herbarum isolated from farmed fish. Diseases of Aquatic Organisms. 94: 17-28.

46. Al-Salahy M (2011) Physiological studies on the effect of copper nicotinate (Cu$\mathrm{N}$ complex) on the fish, Clarias gariepinus, exposed to mercuric chloride. Fish Physioly and Biochemistry 37: 373-385.

47. Trevisan R, Samira F, Jaco J, Marcio R, Afonso C, et al. (2014) Zinc cause acute impairment of glutathione metabolism followed by coordinated antioxidant defenses amplification in gills of brown mussels Perna perna. Comp Biochem Physiol C Toxicol Pharmacol 159: 22-30.

48. Aydilek N, Aksakal M (2005) Effects of testosterone on lipid peroxidation, lipid profiles and some coagulation parameters in rabbits. J Vet Med A Physio Pathol Clin Med 52: 436-439.

49. Aydilek N, Aksakal M, Karakilcik A (2004) Effects of testosterone and vitamin on the antioxidant system in rabbit testis. Andrologia 36: 277-281.

50. Sadowska-Krepa E, Slawomir J, Andrzej S, Stanislaw J, Pawel G, et al (2011) High-dose testosterone propionate treatment reverses the effects of endurance training on myocardial antioxidant defenses in adolescent male rats. Cardiovasc Toxicol 11: 118-127.

51. Wachnik A, Biro G, Biro L, Korom M, Anna G, et al. (1993) Effect of sex 
Citation: Sayed AEDH, Khali NSA (2016) Oxidative Stress Induction in Monosex Nile Tilapia (Oreochromis niloticus, Linnaeus, 1758): A Field Study on the Side Effects of Methyltestosterone. J Aquac Res Development. 7: 416. doi:10.4172/2155-9546.1000416

hormones on copper, zinc, iron nutritional status and hepatic lipid peroxidation in rats. Die Nahrung 37: 28-34.

52. Albayrak Y, Halici Z, Odabasoglu F, Unal D, Oral A, et al. (2011) The effects of testosterone on intestinal ischemia/reperfusion in rats. Journal of Investigative Surgery 24: 283-291.

53. Chandra A, Ghosh R, Chatterjee A, Sarkar M, et al. (2010) Protection against vanadium-induced testicular toxicity by testosterone propionate in rats. Toxicol Mech Methods 20: 306-315.

54. Guzman D, Gerardo B, Ivonne E, Emestina H, Daniel S, et al. (2005) Effect of testosterone and steroids homologues on indolamines and lipid peroxidation in rat brain. J Steroid Biochem Mol Biol 94: 369-373.

55. Verma Y, Rana S (2008) Modulation of CYP4502E1 and oxidative stress by testosterone in liver and kidney of benzene treated rats. Indian J Exp Biol. 46: 568-572.
56. Rio D, Amanda J, Nicoletta P (2005) A review of recent studies on malondialdehyde as toxic molecule and biological marker of oxidative stress. Nutrition, Metabolism \& Cardiovascular Diseases. 15: 316-328.

57. Abd Allah E, Marwa A, Asmaa F (2014) Comparative study of the effect of verapamil and vitamin $D$ on iron overload-induced oxidative stress and cardiacstructural changes in adult male rats. Pathophysiology 21: 293-300.

58. Bagnyukova T, Lida L, Igor P, Lushchak V (2007) Oxidative stress and antioxidant defenses in goldfish liver in response to short-term exposure to arsenite. Environ Mol Mutagen 48: 658-665.

59. Salum E, Jaak K, Priit K, Salum T, Zilmer K, et al. (2013) Vitamin D reduces deposition of advanced glycation end-products in the aortic wall and systemic oxidative stress in diabetic rats. Diabetes Res Clin Pract 100: 243-249.

60. Tufek A, Orhan T, Ibrahim A, Ulas A, Osman E, et al. (2013) The protective effects of dexmedetomidine on the liver and remote organs against hepatic ischemia reperfusion injury in rats. Int J Surg 11: 96-100. 